CUERPO Y ARTE 



\title{
Del híbrido griego al cyborg
}

\author{
From Greek hybrid to cyborg
}

TERESA AGUILAR*

\begin{abstract}
Resumen: Este texto describe la evolución del cyborg desde la época griega hasta la actualidad, especialmente en el mundo del arte, a través del concepto de hibridación. Las fusiones corporales han estado presentes en la historia de la humanidad desde la prehistoria a través de la figura de los teriántropos, en la mitología griega y más tarde en la obra de artistas como Arcimboldo, el Bosco y Leonardo. En la actualidad la figura del cyborg sigue manteniendo su representatividad en el arte con autores como Stelarc o P. Meste y adquiere una gran presencia en el mundo cinematográfico y en nuestro imaginario cotidiano.
\end{abstract}

Palabras clave: Cyborg, hibridación, tecnología.

\begin{abstract}
This text describes the evolution of cyborg from Greek times to the present, especially in the art world, through the concept of hybridization. Bodily fusions have been present in the history of mankind from prehistory through the therianthropes figure, in Greek mythology and later in the work of Renaissance artists such as Arcimboldo, Bosco and Leonardo. Today the figure of the cyborg retains its representation in art with artists such as Stelarc or P. Meste and acquires a strong presence in the film world and in our everyday imaginary.
\end{abstract}

Keywords: cyborg, hybridization, technology.

En su desarrollo, el arte ha puesto sus límites con tanto esfuerzo y los ha respetado tan poco en tanto que divertimento, que lo que advierte de la caducidad de esos límites, todo lo hibrido, provoca una defensa virulenta. T. Adorno

Si hay algo que podamos afirmar con certeza es que el cyborg es un concepto mítico que apunta a lo salvífico y lo indeterminado, ya que su ontología bascula entre lo tradicionalmente considerado como fantástico y al mismo tiempo aparece situado como ente real posible hoy gracias a la tecnología y a la concepción de la pensadora Haraway que le imprime la ontología propia del ser hibridado entre animal y humano, pero que ha

Fecha de recepción: 11/06/2016. Fecha de aceptación: 17/07/2016.

* Profesora de la UNIR. ytemas@yahoo.es Líneas de investigación: Perspectiva filosófica del cuerpo humano en confluencia con las nuevas tecnologías, el arte, la medicina. Teoría cyborg, estudios culturales y teoría feminista. El presente texto es un extracto de algunos capítulos de mi último libro publicado en 2013: Cuerpos sin límites. Transgresiones carnales en el arte. Casimiro Libros, Madrid, (350 págs.) que fue galardonado con el Premio Internacional de Ensayo MADATAC05 ese año. Una investigación sobre el cyborg y las nuevas tecnologías en el cine es mi ensayo Cartografía de la tecnosociedad a través del cine, publicado en 2012 por Alfons el Magnànim. Valencia. Col-lecció Novatores 34 (250 págs.) 
habitado la cultura occidental desde que el sapiens llegó a serlo. Casi nacido en el siglo XXI, pero que sin embargo ha estado presente en el arte desde sus más remotos orígenes, si bien denominado de diferentes formas: teriántropo, centauro, minotauro, cíclope y arimaspo u hombres con un solo ojo, cinocéfalos u hombres con cabeza de perro, andróginos o seres con dos sexos, ástomos o seres que carecen de boca, acéfalos e himantópodas y antípodas, que tienen las plantas de los pies vueltas tras los talones y, en ellas ocho dedos. Los hipopodas viven en la Escitia, poseen figura humana y patas de caballo. Quimera, gorgona, grifo, sátiro, sileno, fauno, sciápodas, arpía, anfisbena, dragón, basilisco, sirena, esfinge, hermafrodita o glíptico, la hibridación del humano con lo que no sea él mismo o la hibridación animal como cruce de distintas especies: animal, planta o cosa, es una constante que se inscribe en la corriente de lo aprotopaico y lo grotesco, al menos desde la Grecia clásica después del paleolítico.

Mientras el teriántropo es una imposibilidad física de pensarse el ser humano despojado de su animalidad en el prehistórico estado de su evolución emergente, los cíclopes griegos o gigantes que poseían un solo ojo, los centauros o híbridos de humano y équido, los grifos formados por cabeza y alas de águila con cuerpo de león, las arpías con cuerpo de rapaz, busto humano y cuerpo de serpiente, las sirenas compuestas de rostro humano y cuerpo de pez, se constituyen en seres de bestiario medieval como síntoma de la indiferenciación de la materia cárnica en un mundo en que ésta poseía la plasticidad típica del demiurgo creador, mundo por otra parte pleno de materia, desbordante, como si se tratara de una carne del mundo medieval que había sido destinada a carnar el corpus mundus de la Naturaleza; barullo exponencial y caótico capaz de engendrar a su voluntad los más inimaginables seres posibles salidos de una mente carnal y biológica expandida en el ubicuo mundus de una Edad Media que aún pensaba que la tierra era plana, pero que la imaginaba como un entorno edénico y paradisíaco en sus orígenes, que intentaba captar la esencia de un tiempo mítico en que todas esas criaturas fueron creadas de la nada, como el acto mágico iniciático en que los pintores parietales sacaban a la luz teatral y fantasmagórica de sus antorchas, los seres animales que pululaban por el mismo universo que el suyo proyectados en la piedra. En contraposición, el orbe circular abraza el esplendoroso mundo de la carne como la orgia más sexual, comunal y transgresora sólo por haber descubierto en la profundidad de la tierra el Domus Aurea, y así reapropiarse del escenario cyborgiano que entonces fue romano. Momento politeísta en que también sólo eran los dioses los poseedores de la virtud de transformar los cuerpos, escenario abandonado por el monoteísmo que sólo ve en un cuerpo único de apariencia humana la salvación de todo el género al que representa. En este sentido el politeísmo es aliado de una ontología cyborg liberadora de una sola constitución óntica para proyectarla en la plurimorfidad de la carne como posibilidad de libertad. Este aspecto es el que es retomado por Haraway en su discurso sobre el cyborg, ente salvador gracias a su plasticidad que le permite fusiones corporales impensadas para un pensamiento liberal tradicional e ilustrado, no para el pensamiento preparado para la vuelta a la confusión carnal propia de épocas medievales irónicamente, tiempos en que el único cuerpo humano era hipostasiado como ente acaparador del sufrimiento de la humanidad, entonces, cuando tales ideologías dominaban el panorama surgen diásporas carnales que apuestan por la hibridación como forma explicativa de una otología estanca. Gracias al pecado el arte del cuerpo humano 
se metamorfosea tal y como sucedió en el pensamiento griego politeísta que veía en esa versión no apolínea una evasión salvadora del ser encastrado en su esencia humana tal y como había sido proyectada por un pensamiento de proporciones áureas.

Contrariamente a la ideología mítica que promociona entes monstruosos y metamorfoseados, la estética artística del canon griego nos presenta los ejemplos más humanamente perfectos que la historia del arte haya registrado, frente al esquematismo pictórico que el arte románico de la cristiandad ofrece al orbe: seres esquemáticos, falta de proporciones en la figura humana, etc. Aspecto que el Renacimiento retoma del arte griego para restaurar la imagen de un cuerpo humano bello y proporcionado, en constante antítesis con la mitología que crea, de lo que se deriva la propia conciencia griega de que tal mitología no formaba parte de la realidad, sino de un universo pedagógico del que el humano social se despegaba por completo, prefiriendo representar el cuerpo cotidiano de los seres que participaban en los juegos olímpicos y en la gesta de un mundo demasiado real que entraba en la tragedia y repudiaba el mito, al menos en el terreno del arte.

La hybris griega simboliza la desmesura que excede los límites de lo designado por los dioses, por eso es condenada mediante la némesis o justicia que restaura la hybrys como desmesura. En la mitología griega los seres hibridados adquirían esta condición tras haber superado los límites y la lista de personajes mitológicos griegos condenados por su hybrys es extensa. La hibridación es un fenómeno de transgresión de los límites de lo consensuado y de los del cuerpo, ejemplificados en la mixtura de anatomías en un mismo ser. La esfinge ha sido la criatura hibridada que ha captado la atención de varios autores, desde el enfoque heideggeriano, al pensamiento de Freud o al de Lévi-Strauss. Este último la hace símbolo y metáfora de la imposible unión existente entre cultura y naturaleza, mientras que para Freud es el enigma de la esfinge el foco principal de su estudio desde el que descubre el origen de la sexuación.

El enigma que la esfinge le plantea al humano tiene como respuesta la propia definición de la condición evolutiva y ontológica de lo que es ser humano, tal y como advierte Arsuaga, al proponer qué es aquella cosa que por la mañana anda a cuatro patas, por la tarde a dos patas y en el ocaso con tres, ejemplificando con ello no sólo la historia evolutiva de toda vida humana, sino también la propia situación de la evolución biológica de la especie.

Para Adorno estas figuras hibridadas en el arte al contrario de manifestar el caos de la razón suponen una razón ordenadora y el terror que provocan no dimana por tanto del caos, sino de la expresión de la fragilidad humana:

Ya en las figuras mixtas impera una razón ordenadora; la historia de la naturaleza no ha dejado que sobrevivan esas cosas. Esas figuras son terribles porque recuerdan la fragilidad de la identidad humana, pero no son caóticas: la amenaza y el orden están mezclados ahí. En los ritmos repetitivos de la música primitiva, lo amenazante dimana del principio de orden mismo. La antítesis de lo arcaico está implícita en èste; el juego de fuerzas de lo bello es un principio de orden; el salto cualitativo del arte es una transición mínima. (Adorno, 2004: 80-81)

Pintores renacentistas como el Bosco, Arcimboldo y da Vinci retomaron este estilo figurativo a caballo entre lo cómico, lo mágico, lo elusivo, la vanitas y la evasión, inaugurando 
en el terreno del arte, ya no de la decoración de interiores, la temática de la hibridación corporal como reflejo de un mundo de metamorfosis y transgresiones carnales que después retomará el movimiento surrealista.

Las fusiones corporales han estado presentes en el imaginario cultural de la humanidad desde épocas muy remotas. Hemos de remontarnos al paleolítico superior para encontrar los teriamorfos en una cueva prehistórica de Francia. La figura hibridada de un ser humano con un ser animal que tanto impresionó a filósofos como Bataille y Blanchot, lo que hoy se denominaría cyborg, pero que es un teriamorfo paleolítico que sólo el origen puede descubrir como nominación primera. Después viajar hasta la mitológica Grecia clásica para encontrar los centauros, esa simbiosis carnal entre ser humano y caballo, las sirenas y las esfinges que opta, que opta por fusionar al ser humano con un león. Después, en la imaginación medieval surgen los bestiarios, con los que se intenta catalogar el mundo imaginario de animales increíbles cuya existencia relatan viajeros o alucinados, para expresar lo inconmensurable de las criaturas divinas.

Ya en el siglo XVI los seres grotescos ${ }^{1}$ inundan los ornamentos y se introducen en la decoración con las glípticas grecorromanas, aquellas representaciones de seres compuestos por cabezas, que ofrecen todas las combinaciones posibles entre animal y humano y representaciones surrealistas como cabezas con patas, cabezas con un cuello de pájaro o de cuadrúpedo... cuatro, cinco, siete rostros u hocicos de animales se unen en un mismo organismo". A las piedras grabadas con estas glípticas se les atribuían características mágicas de protección y al lugar donde estaban ubicadas. También la drôlerie gótica, mixtura de animal y humano que bordea los entrelazados vegetales de los libros góticos que bordeaban la página y que es ampliado por Gombrich a las gárgolas, ménsulas y crucerías. Estos híbridos son posteriores al primitivo animal planta que data del siglo XII y que aparece en las iniciales como influencia de los bestiarios. Para B. Fernández la aparición del híbrido animal-humano obedece a un interés nuevo en estas drôleries góticas que pretenden satirizar al humano a base de hibridarlo con animales. Sin embargo es la función protectora que estas figuras pudieran ofrecer la tesis más extendida desde E. Loewy, quien señaló el poder apotropaico que ya ofreciera la cabeza de la Gorgona en los

1 El origen de lo grotesco como término que rápidamente se populariza, y antes de la caracterización que de él hiciera el famoso estudio de Bajtin, se localiza en 1480, cuando son descubiertas en Roma las pinturas romanas del Domus Aurea de Nerón enterradas, por lo que grotta como forma latina es cueva que a su vez deriva de la forma griega que significaba ocultar. El sustantivo italiano grottesco que se corresponde con el español grutesco (que se traduce del italiano grotteschi, o procedente de las grutas) fue el término elegido para denominar tanto a las pinturas descubiertas en aquellas ruinas arqueológicas que efectivamente quedaron bajo tierra, sugiriendo el evocador mundo de los subterráneo como origen de este vocablo, como al estilo decorativo que se extendió durante el siglo XVI. La Domus Aurea de Nerón, de 300 metros de longitud por 90 de ancho, fue la nueva residencia que levantó después del incendio del 64 y que aparece decorado por frescos poblados de seres mitológicos y sátiros, estilo que será reapropiado por la decoración del siglo XVI eligiendo motivos sueltos que integran según el gusto del Quattrocento con un enriquecimiento de los cuerpos fantásticos ya presentes en el Medioevo: grifos, esfinges, tritones dotados de alas. Signorelli en Umbría será el máximo representante junto con Fillippino Lippi en Florencia inaugurando un estilo decorativo presente en las tapicerías, ornamentos y telas y papeles pintados que alcanzaron ejemplos fastuosos en las Logias de Rafael y Giovanni da Udine en el Vaticano. (B. Fernández, De Rabelais a Dalí).

2 Citado por B. Fernández en De Rabelais a Dalí la imagen grotesca del cuerpo, p. 27, nota 23, de J. Baltrusailtis, La edad Media fantástica. Antiguedades y exotismo en el arte gótico. Madrid, Cátedra,1983.p.p 22-31 
escudos, vasijas y armas griegas, a lo que Gombrich añade el factor cómico que liberaría de la angustia por la contemplación de las figuras grotescas, a modo de catarsis liberadora, idea que subsiste hoy en el concepto de cyborg propuesto por Haraway como un ente de realidad y ficción y una promesa liberadora de la condición humana. Iniciándose ya en el siglo XVI interesantes debates sobre la finalidad y la estética de estas representaciones entre Vitruvio y Horacio, que defendían posturas opuestas en cuanto a la procedencia de estos objetos y su inclusión en la categoría de arte en base al concepto de su ajuste con lo real y existente del pensamiento racionalista que considera belleza a lo que se ajusta sólo a la realidad y la razón, y la posición de Horacio, que permite libertad creadora en el artista. El arte como reproducción fiel de la realidad, máxima de la teoría del arte renacentista (Alberti, De la pintura, 1435) se enfrenta a esta novedad de lo grutesco: "la negación del espacio y la fusión de especies, la ingravidez de las formas y la proliferación insolente de híbridos, (...) en este vacío lineal maravillosamente articulado, formas semivegetales, semianimales, figuras sin nombre surgen y se confunden según el movimiento gracioso o atormentado del ornamento. De ahí nace un doble sentimiento de liberación, respecto al espacio real donde reina el peso; y respecto al orden del mundo que gobierna la separación entre los seres. (...) El dominio de los grutescos es casi exactamente la antítesis de la representación, en el que las normas estaban definidas por la visión perspectiva del espacio, y la distinción, la caracterización de los tipos"3.

Imaginativo, sensual y sensorial podían y debían ser llamadas arte, ya que éste para ser nominado como tal había de circunscribirse a la recreación de lo canónicamente establecido como bello, a la reproducción mimética de la realidad y a la adecuación de esta con lo visible y permisible, cuando en sus prácticas cotidianas ninguno de estos cánones era mayoritario. Sin embargo la propia transgresión del cuerpo de Cristo ensalzaba el dolor y las heridas y habían de ser acrisolados bajo el concepto de racionalidad y belleza, sin que tampoco despertara pavor la visión de las gárgolas y de las decoraciones talladas en madera que jalonaban los frisos y bancos de iglesias y catedrales, también llamada marginalia, por el papel secundario que ostentaba en las decoraciones. Las encontramos en los márgenes de los manuscritos ilustrados; en los relieves arquitectónicos de los pórticos y columnas de las iglesias; en las vidrieras; en las sillerías de los coros; en las cornisas de los tejados, en las remotas tierras y océanos de los mapas, y, en general, en todos los espacios secundarios del arte en los que el ingenio y la imaginación hacían convivir razas humanas de extraña morfología con animales reales o fabulosos, criaturas híbridas, seres mitológicos y bestias de asombrosa naturaleza.

La convivencia con lo grotesco era más que habitual y necesaria sobre todo si le atribuimos el poder protector mágico por el que podían ser reproducidos. De la misma forma que el cuadro con escena de caza decoraba los comedores de grandes masas de población en su intimidad hogareña por medio de recrear pictóricamente el carácter sangriento del alimento que iban a tomar sin que eso provocase náuseas a los burgueses, la imagen del Cristo que figuraba sobre el lecho matrimonial tampoco los espantaba por considerarlo el símbolo más alejado de la concupiscencia y el placer carnal. Es por eso que el repudio hacia el arte que hoy se llama abyecto o no bello ha sido un falso sistema moralista que se encubría bajo los

3 A. Chastel, p. 29, citado por B. Fernández . op. cit., 
términos de belleza y racionalidad cuando ninguno de los dos era verdaderamente impugnado en la práctica, sino exaltado y exhibido con profusión en las iglesias y los hogares.

Lo grotesco, frente a lo abyecto o al arte del trauma, impugna el orden de la racionalidad y es por eso grotesco o excéntrico o monstruoso y hace que los defensores de la racionalidad y de lo que debe ser visible condenen a lo grotesco al interior de la obscuridad y lo que no debe ser visto, ya que perturba el orden racional de la mente lúcida, y se denomina como lo que está oculto en la cueva, la gruta, el lugar litúrgico donde se procede al intercambio carnal y la inhumanidad. Puesto que a los ojos del racionalismo ilustrado la galería de lo monstruoso quedaba circunscrita a la maravilla de la naturaleza y al milagro de lo deforme como raro, único y objeto de museo, que existía como norma que confirmaba la regla. Así que mientras en el Barroco lo monstruoso formaba parte aún de la masa poblacional y se leía como elemento liberador del peso de la razón y como exceso de la carne y como puerta abierta a la imaginación que sorprende y maravilla, en la ilustración lo grotesco se circunscribe a la esfera de la naturaleza y se desprende del carácter socializador y liberador del espíritu que le precedía, para ser considerado un error de la razón y no un motivo liberador para evadirse de ella, aunque sólo fuera con efecto catártico y la circunscribe bajo el modelo médico-científico estudiable a través de los gabinetes de excentricidades. Lo feo y anormal se proscribe frente al canon ideal de perfección, simetría y orden. Sin embargo lo esencial del arte como actividad simbólica que no se limita a ser reflejo de una realidad objetiva hace que pintores como Goya o Brueguel incidan en esos aspectos telúricos que atentan contra lo racional y tienden a la metamorfosis humana como forma de explicación antropológica del ser humano.

Los cuadros del Bosco están poblados de esos seres cyborgizados como denuncia de la vanitas holandesa, tema típico de los pintores de la época. El Bosco incide sobre los límites del cuerpo a base de penetrar de manera surrealista en la conciencia humana al pintar millares de criaturas hibridadas en el escenario de un paraíso terrenal que se ha vuelto loco, puesto que el móvil que guía su inventario cyborgyano es moralizante, mostrando los pecados capitales y los pecados de la carne, las consecuencias del exceso del juego y de las tabernas o la vida licenciosa del clero a base de presentar unos cuerpos sin límites, hibridados con animales, plantas u objetos inanimados. Los pecados de la carne son representados literalmente como transgresiones carnales físicas que son sufridos por los cuerpos humanos que se transforman y transgreden su anatomía humana para hermanarla con animales u objetos o plantas. La transgresión de la carne conduce a un estado anómalo e inhumano que sirve de modelo aleccionador de las conciencias en la religión católica aleccionando las mentes a base de recrear un universo lleno donde estas criaturas pecan y transgreden su carnalidad humana, en un éxtasis de la materialidad según los miles de figuras que pueblan ese universo lleno de materia que se excede a sí misma, se fusiona y se contamina o poluciona, pues el exceso de lo material conduce al vértigo de la amoralidad, de la locura y del mundo caído en pecado, pero también denuncia la maleabilidad de la materia que es un ente común poblado y denso que llena el espacio del mundo según una carne indiferenciada que no posee límites, una verdadera carne del mundo que denuncia a lo orgánico como un ente metamórfico que participa de las otras carnes de las plantas, o las cosas inorgánicas, así como los animales. Aunque lo sorprendente es que sean los colores vivos y claros y la ausencia de negro en sus obras lo que nos haga pensar 
sobre la doble intencionalidad de su pintura, vista ya no como didáctica ejemplarizante o alegoría de la espiritualidad, sino con otra lectura paralela que lo lee como expresión real del mundo y los comportamientos de sus ocupantes, que irónicamente habitan un paraíso de colores y naturaleza mágica.

También Pieter Bruegel el Viejo, otro pintor flamenco del siglo XVI, pintó magistralmente el mundo infernal y sus criaturas. Lo hizo en los grabados de Los siete pecados capitales, en 1558, y las grillas que en ellos dibuja son más bulliciosas y divertidas que amenazantes. Lo hizo también en algunos de sus cuadros, como La caída de los ángeles rebeldes o Dulle Griet, pero en ellos el aspecto terrorífico predomina sobre el lúdico.

También en el siglo XVI, Arcimboldo (1527-1593) representa esa fusión de la carne a base de representarla sustituida por otra cosa, especies vegetales y animales, pero también sustituida por libros, en su cuadro El bibliotecario, en el que una figura humana se representa por la aglomeración de libros dispuestos en diferentes formas, como si la carne humana pudiera tener una existencia real también si estuviera hecha de conocimientos o como si estos convirtieran al individuo de letras en un rígido ente constituido a base de planos y geometría sin que nada de ello recuerde a la humana condición cárnica que lo constituye. Los seres humanos vegetales representados en las cuatro estaciones y en los cuatro elementos, son por el contrario, formaciones vegetales que representan la caducidad de la vida natural y la naturaleza cambiante de las estaciones se constituye en alegoría principal que equipara a las distintas edades por las que el ser humano pasa en la vida y su consustancial decadencia y precariedad existencial que equipara a la carne humana con la perecedera existencia de los vegetales y las frutas por el inexorable paso del tiempo. Sin embargo, es en su serie de los cuatro elementos donde la teoría merleaupontyana sobre la carne adquiere toda su dimensión cuando se refiere a ella como elemento más que como sustancia, en el sentido presocrático de los cuatro elementos que componen el mundo. La carne del aire es la de los pájaros, la del agua la de las especies marinas, mientras que la carne de la tierra es la de los cérvidos y fieras, siendo el fuego la materia ardiente surgida de las velas. La carne humana está constituida por la misma carne de las cosas naturales del mundo. La transgresión carnal es en el siglo XVI objeto de atención por algunos artistas que la utilizan siguiendo la tradición de la carne transgredida y fusionada desde épocas paleolíticas, si bien en Arcimboldo la fusión es simbólica y sustituye a la silueta humana que representa a base de rellenarla con elementos biológicos que sustituyen a la carne, en la línea más actual de los proyectos sobre bioarte. Para el Bosco, sin embargo, se trata de una cyborgización plena heredera directa de las glípticas grecorromanas, pero que ambos autores se confirman como los precursores del movimiento surrealista, en especial de autores como Dalí, Magritte o Marx Ernst, que consiguen trasladar el statuto del cyborg pictórico hacia el universo onírico de lo inconsciente desde la biologicidad moralista en que estuvo situado en las épocas precedentes.

En el Renacimiento los intentos de Da Vinci por injertar alas al cuerpo humano constituyen una excepción respecto a sus coetáneos al interpretar la cyborgización animal como una mejora tecnológica que el ser humano debe reapropiarse, en la línea de los actuales trabajos de Stelarc.

El siguiente hito en la construcción del cyborg que comienza a hacerse tecnológico, el hombre pájaro pretendía ser un cyborg que preludiaba el nacimiento de los aparatos vola- 
dores que hoy consumen ingentes cantidades de una energía que escasea a base de intentar aproximarse a la imagen del pájaro como modelo tecnológico, no como animal con el que el humano puede intercambiar su cabeza como en las figuras boschianas o los teriamorfos del paleolítico. Leonardo destaca la anatomía como diseño tecnológico que permite gracias a su implementación orgánica mejorar las capacidades biológicas de la precaria anatomía humana. Mientras Arcimboldo inaugura el humano-vegetal según el hombre árbol que representa el invierno y el resto de estaciones, pero también animal en el aire, la tierra y el agua, El Bosco profundiza en el humano-animal-cosa y Leonardo inaugura el homo-tecnología, el cyborg más conocido en la actualidad como icono emergente del capitalismo avanzado efusivamente exhibido a través de la cinematografía.

La figura del cyborg es en la Edad Media un agente que manifiesta la libertad de la materia de supuesta creación divina para crear seres fantásticos que le sirven al régimen católico como ejemplo moralizante para la educación de la masa. En el Renacimiento el cyborg sale de ese marco estrecho de la teodicea para aproximarse a la idea del cyborg como ente liberador que libera a la materia cárnica de su condición terrena o que emula y transgrede esa carne para reflejarla. Mientras que el racionalismo de la Ilustración confina al cyborg al terreno de lo médico y lo raro es aquello marginado por la naturaleza como anormal y desviación del orden natural y racional, en la etapa posmoderna el cyborg surge manteniendo su impronta clásica de ser fantástico y de ser liberador, también como ente que ya es realmente posible, no fruto del imaginario, construyéndose una existencia a medio camino entre ambos polos que para la pensadora Haraway simboliza el poder liberador de esta figura transfiguradora que detenta el deseo de un mundo mejor e inexplorado apostando por la comunión de la carne con lo que no es ella misma. El carácter político que esta ontología supone, como status que en la racionalidad se lo proscribió sin voz ni existencia racional, sino como existente en el margen, es la voz de lo proscrito que subvierte su condición muda largamente promocionada en los siglos ilustrados como condición deseable para el ser humano poshumano que huye de esencialismos, raza, clases sociales o género. El potencial subversivo del cyborg es también un medio de denuncia de la tecnología armamentística para artistas como Meste, o como una potente manera de mejora del diseño anatómico, en la línea de Stelarc. Las extensiones corporales dejan de ser naturales para pasar a estar construidas de piezas mecánicas que se acoplan a la anatomía humana, bien para denunciar el uso indiscriminado de artefactos de la muerte, bien para constituirse en prótesis que amplían el cuerpo cyborgizado.

El Transhumanismo, la neofilosofía tecnófila de nuestro siglo, plantea en su vertiente artística y a través de su propio manifiesto artístico, en la línea de las vanguardias que se precien, cyborgs inmortales e inmunes a cualquier enfermedad, acorde con las premisas de su ideario, que ve la naturaleza humana como un work in progress, algo a medio terminar, una materia modelable fácilmente transgredible.

Vita-More escribió el Manifiesto de Extropic Art: “Aestehetics of Memetic Evolution" en $1997^{4}$. El trabajo artístico de Natasha Vita-More gira en torno a Primo 3M+ radical body design, un cuerpo que combina ingeniería estética con nanotecnología, AiS: artificial intelligent skin (piel artificial inteligente), IA: Intelligence Augmentation

4 La versión en inglés del manifiesto puede ser leída en: http://www.extropic-art.com/contents.htm 
(inteligencia ampliada), y un cuerpo compuesto de partes reemplazables que se pueden actualizar, ampliar y optimizar. Primo $3 M+$ es un prototipo de cuerpo del futuro, un diseño conceptual que comprende una longevidad mucho mayor que la actual. Su diseño es multifuncional, desmontable, cambiable, actualizable y ampliable mediante sensores. La arquitectura del cuerpo de Primo está pensada para una movilidad y flexilbilidad duraderas y ha sido realizada por un grupo de científicos entre los que se encuentran Max More, Marvin Minsky, Robert Freitas, Michael Rose, Greg Fahy, Ralph Merkle, Alexander Sasha Chislenko, Roy Walford, Gregory Benford, Robin Hanson, Vernor Vinge, y Hans Moravec. El interior del cuerpo es extensible y ofrece un novedoso metacerebro y unos sentidos avanzados, hipersentidos. La espina dorsal, producto nanotecnológico, cuenta con un sistema de comunicación controlado por una unidad de Inteligencia Aumentada (AI) Tiene un sistema inmunitario garantizado contra todas las patologías. El servicio de llamadas es ilimitado y su sede está localizada en el Asteroide Belt.

Hoy que los humanos han adquirido el status de dioses gracias a la tecnología, se transforman a sí mismos corporalmente con la esperanza de ser los cadáveres más bellos del cementerio al tiempo que conviven en una mísera sociedad globalizada que hipostasia el capitalismo como única forma de vida en el planeta, generando lo que hoy se denominan bolsas de pobreza, metonimia perfecta para denominar la basura, la cual ya sólo puede ser concebida metida en una bolsa de plástico, para no contaminar el planeta, como síntoma de cauterización para el humano que la acumula en ella, pero como síntoma destructor para la tierra que la reconoce como cuerpo extraño. Por eso el cyborg es hoy algo más que el tradicional cuerpo hibridado de la historia del arte, porque posee una ontología que le ha sido otorgada por su propia constitución negada a lo largo de la historia después del proceso de posmodernidad, o bien un discurso propio que le dotara de una identidad propia, diferente o incluso deseable, deseable en términos no falologocéntricos y desde la herencia vivida y discursiva de una femineidad que repudia y reivindica al mismo tiempo una ontología otra, tras siglos de opresión por razón de su condición sexuada, pero también de raza y sobre todo de clase. Por eso el cyborg tampoco surge de la nada de la teoría posmoderna, sino que emerge como una reinvención de lo que el arte, sobre todo, se ha empeñado en representar a través de las diferentes épocas y frente a la parálisis de la imaginación, el sueño o el divertimento.

\section{Bibliografía}

Adorno, Theodor. W (2004): Teoría estética. Akal, Madrid.

Aguilar, Teresa (2008): Ontología cyborg. El cuerpo en la nueva sociedad tecnológica. Gedisa, Barcelona.

Aguilar, Teresa (2012): Cartografía de la tecnosociedad a través del cine. Alfons el Magnánim. Valencia.

Aguilar, Teresa (2013): Cuerpos sin límites. Transgresiones carnales en el arte. Casimiro Libros, Madrid.

Baltrusaitis, Jurgis (1983): La edad Media fantástica. Antigüedades y exotismo en el arte gótico. Cátedra, Madrid, pp. 22-31. 
Fernández, Beatriz (2004): De Rabelais a Dalí la imagen grotesca del cuerpo. Universidad de Valencia.

Haraway, Donna J (1995): Ciencia, cyborgs y mujeres. La reinvención de la Naturaleza. Cátedra, Madrid.

Vita-More, Natasha (1997): Aestehetics of Memetic Evolution http://www.extropic-art.com/ contents.htm 